\title{
Resolving the Acquisitions Dilemma: Into the Electronic Information Environment
}

\section{Eldred Smith}

\begin{abstract}
Editor's note: This article is the second part of a series on scholarly communications and serials prices.

This paper analyzes the present serials acquisitions crisis as the latest manifestation of the instability of the economic system supporting scholarly communication, which places an increasingly intolerable burden on the research library. It reviews various solutions that have been proposed to solve this crisis, arguing that none is achievable as long as the present economic system continues. It proposes a resolution to this dilemma, drawing upon the capabilities of new electronic technology, through which the economic burden on the research library will be reduced or even eliminated, and the system of scholarly communication improved.
\end{abstract}

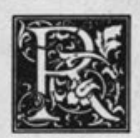

esearch librarians once again confront a serious acquisitions crisis. Their continuing, historic struggle to maintain the strength, quality, and effectiveness of their collections is jeopardized, as it has been periodically in the past, by their inability to meet expanding prices and proliferating publication with relatively stable budgets. The present crisis has been precipitated by recent, quite substantial increases in the cost of scientific, technical, and medical journals.

Various suggestions have been made for dealing with this crisis. They range from proposals to control the cost and proliferation of journals; to increased resource sharing; to changes in the practices of scholars and scholarly publishers. Unfortunately, each of these solutions presents its own difficulties. Moreover, none of them promises more than a short-term adjustment, a period of temporary equilibrium until the problem arises again. Consequently, the crisis precipitates a dilemma, a problem with no satisfactory solution. Indeed, it is simply the latest episode in the research librarian's long, heroic, but inevitably losing struggle to acquire, organize, and preserve the record of scholarship.

But is there no satisfactory solution? Can this struggle be brought to a successful conclusion? Yes, it can, through proper employment of new electronic information technology. Indeed, in this respect, the current serials crisis may, ironically, have a substantial value: not only does it demonstrate how serious the acquisitions dilemma has become, but it also shows how that dilemma may finally be resolved.

\section{THE SERIALS CRISIS}

The present research library serials crisis is now widely recognized. Identified initially by acquisitions and serials librarians, through their journals and meetings, it now has the attention of re- 
search library directors and their organizations. The American Library Association (ALA) established a blue-ribbon task force, chaired by a former executive director and including publishers and book trade representatives in ALA's membership, to work on the problem. The Association of Research Libraries (ARL) has sponsored two major studies of serials acquisitions. ${ }^{1}$ ARL is pursuing a program of action to deal with the particular issues identified in these analyses. At its 1989 spring membership meeting, the ARL membership resoundingly approved a special dues assessment in order to finance an activist approach to deal with the serials crisis. This action is a sure indication of ARL's seriousness.

Concern about this crisis is no longer restricted to librarians. Academic administrators have expressed apprehension and called for action. Scholarly publishers have convened special meetings involving scholars, librarians, and commercial publishers to discuss possible solutions. In spite of all this activity, however, few positive results are visible. The prices of serials, particularly scientific, medical, and technical serials issued by a handful of commercial publishers, continue to increase substantially beyond the average rate of inflation. New serials continue to appear at an alarming rate. Research library acquisitions budgets, despite special infusions of funds, are increasingly strained to maintain even past levels of coverage, leaving aside the need to purchase new titles.

A variety of causes has been identified for this crisis. The decline of the dollar has seriously damaged research libraries, a large percentage of whose acquisitions are published in Western Europe. The exponential growth of scholarly publication, which doubles every ten to fifteen years, exceeds research library acquisitions budget capabilities. Dual pricing places an increasingly heavy burden on research libraries. Finally, the increase in publication of scholarly materials by commercial houses has been pinpointed as an especially destabilizing influence.

All research libraries, even the wealthiest, have been affected by these develop- ments. Long-established acquisitions programs are being distorted. Serial subscriptions are being cancelled. Monographic purchases are being reduced. Operations and services are being constrained as the funding for vacant staff positions is used for acquisitions. Research libraries are able to acquire fewer and fewer scholarly publications, to cover less and less of the record of scholarship. And as they seek to adjust to these pressures with cooperative programs, such as increased resource sharing, research librarians seem only to be compounding the crisis by stimulating further price increases.

\section{WHO'S TO BLAME?}

The tremors radiating out from this crisis have inspired a number of accusations. Every participant in the scholarly communication process has received a share of blame. For research librarians, the primary culprits are the large commercial publishers, whose aggressive pricing policies and undisguised profit motive have made them singular objects of attack. The research librarian has also pointed a finger at scholars, whose ever-expanding publication is seen as stimulated perhaps as much by tenure and advancement pressures as by the value of research. Research librarians reproach scholarly publishers, particularly universities and societies, for yielding an increasing portion of their domain to the for-profit sector. Scholars and scholarly publishers blame research librarians for not securing the additional resources that researchers need to keep up with expanding publication. Commercial publishers have aggressively joined this attack as criticism of them has continued and mounted.

In fact, some critics observe that all participants in the scholarly communication system must bear some share of the blame. But should they? Is anyone really at fault? Aren't the participants simply carrying out their assigned roles? The commercial publisher's profit motive clearly drives up prices, but can or should a business be blamed for seeking to maximize its profits? The scholars' interest in publications forces the exponential growth of the literature, but isn't the scholars' fundamental respon- 
sibility to share the results of their research? Scholarly publishers' historic concern has been to monitor and distribute the product of scholarship. However, the business side of this-by definition, nonprofit-enterprise has not generally been attractive to scholarly publishers. Why should they be blamed for deferring an increasing share of their burden to the commercial sector, particularly as the integrity of peer review and the quality of editorial judgment are not threatened? Research librarians are expected to fulfill their responsibilities within the constraints of limited resources, competing aggressively but understandingly within the context of the generally expanding needs and increasingly limited capacities of the research university. Can research librarians be faulted for not pursuing acquisitions funding increases more aggressively under such circumstances?

If the participants are not to blame, perhaps it is the system itself that is at fault. Perhaps the process of scholarly communication needs an overhaul. More and more, this view seems to be shared, at least among research librarians. ${ }^{2}$

\section{IS THERE A REMEDY?}

To assert simply that the system of scholarly communication needs to be changed or adjusted is of little practical value. The present system is centuries old, well established, and quite complex, and it includes a number of major participants. If change is to be achieved, it must be clearly and explicitly identified. Its dimension must be established. Is it, for example, to be a relatively minor adjustment, a correction, or a more substantial reworking? Whom will the change most affect? What are the prospects for success or failure? Finally, it is essential to determine who, among the various system participants, must be enlisted in the change effort.

\section{Suggested Changes}

Research librarians have recently proposed a number of specific changes. One cluster of suggestions focuses on the acquisitions process. These suggestions range from standard advice about knowledgeable consumerism, to refusing to purchase particularly high-cost items (or items whose cost has accelerated beyond the standard inflationary increase), to boycotting certain publishers. All of these proposals are directed to the same goal: controlling and stabilizing price increases so that present acquisitions programs can continue and present balances among disciplines can be maintained.

Other suggestions relate to securing additional acquisitions funds. Such an approach continues to receive substantial support, often including activelobbying by scholars at the local level. Publishers, both scholarly and commercial, encourage it. Expanding cooperative research library resource-sharing programs, which seemed to offer such promise during the 1970's funding crisis in higher education, is still being advocated and pursued.

\section{Perhaps it is the system itself that is at fault. Perhaps the process of scholarly communication needs an overhaul.}

Considerable interest is being shown in changing the scholarly communication process. In particular, research librarians seek to enlist the support of the higher education community in reversing the trend toward the increasing commercialization of scholarly publication. They wish to convince universities and scholarly societies to enlarge their publishing roles, to recapture journals that have been ceded to the commercial arena, and to expand their publishing programs to include desired new titles, rather than to have journals issued-by default-by commercial houses.

Beyond this, research librarians discuss ways of limiting the continued rapid growth of scholarly publication by seeking modifications in long-established practices and mechanisms. These mechanisms, such as tenure requirements or expectations, seem to encourage unnecessary and even redundant publishing activity. In undertaking such efforts, librarians hope to form alliances with scholars who find fault with the present system and to influence scholarly organizations and academic administrators. 
There also exists renewed interest in expanding lobbying activity in order to stabilize and extend the gradually declining level of federal support for research library acquisitions programs. Some research librarians hope to recapture the priority support of the $1960 \mathrm{~s}$, perhaps as part of a once hoped for "peace dividend." Finally, technology is seen as a possible solution to this and other research library problems.

\section{Mitigations}

Yet even as research librarians develop their strategies and gather themselves for combat, they seem to display a significant lack of conviction about their prospects for success. They know that they do not occupy a strong market position. Talking about knowledgeable consumerism costs little; accomplishing it may be quite expensive. Certainly, automated systems make it easy to gather and analyze data. This, in turn, strengthens research librarians' ability to identify and compare options. However, it is not clear that, having done this, librarians will be in a position to exact savings that are any greater than the costs of the analysis.

Research librarians must continue to acquire as much as they can of the record of scholarship. It is their historic and enduring role. Their options are extremely limited. They may occasionally refuse to buy expensive items. They may cancel a few serials. However, they do not have the practical ability to make a major impact on their market.

Nothing illustrates this fundamental weakness better than research librarians' inability to mount an effective boycott. Certainly, an action of this kind would exert a significant and rather immediate influence on the commercial publisher. If North American research libraries successfully boycotted all of the publications of only one or two major publishers for even a brief period of time, those publishers and their colleagues would receive a very clear message. However, such a boycott is simply not possible. Not only would it be of highly questionable legality, but it would also seriously undermine research librarians' abilities to meet the needs of their primary clients-scholars. Under these circumstances, an attempted boycott would probably prove far more disastrous to research librarians than to the publishers against whom it was directed.

Securing funding increases is the research librarian's time-honored mechanism for maintaining acquisitions programs. Individual libraries and the research library community as a whole have been generally successful in obtaining additional funds in times of difficulty. This practice continues through the present crisis, even though many of these increases are being identified specifically as temporary or short term. While academic administrators and fiscal officers may grumble and object, additional acquisitions funding in time of need is an issue with strong faculty support. Such support is critical within the academic environment. Nevertheless, analysis indicates that research library purchasing power has been losing ground for some time in relation to scholarly publication growth and inflation. ${ }^{3}$ Furthermore, research librarians are scarcely a decade removed from the doldrums of the 1970 s. Both the severity and the relative frequency of recent fiscal pressures present the specter of a continuing hand-tomouth existence.

\section{Nothing illustrates this fundamental weakness better than research librarians' inability to mount an effective boycott.}

The bright promise of resource sharing has become quite dim in practice, at least among and between research libraries. Research librarians have been reluctant to rely heavily on each other's collections, particularly recognizing the weak infrastructure that exists for prompt and effective exchange of materials. In addition, evidence suggests that publishers, both scholarly and commercial, are prepared to compensate for reductions in research library sales volume 
by increasing their research library prices. Fewer copies may be purchased by libraries, but total library expenditure will probably continue at about the same rate of increase.

Research librarians are not likely to persuade scholarly and higher education institutions to recapture the portion of scholarly publication that has been shifted to commercial houses, or even to reduce this trend. There are good reasons for such transfer, after all. The transfer relieves universities and societies of the burden of subsidizing and marketing the product - obligations that have been unattractive and costly to academic enterprises-while enabling them to retain editorial control. It also relieves scholars of page charges and other direct costs connected with scholarly publication at a time when federal and other grant support is declining. And the transfer expands publication opportunities.

Humanities and many social sciences disciplines have not experienced the degree of commercialization that has occurred in the hard sciences and technology. These disciplines may express sympathy, particularly if they believe that their sales are likely to suffer in the reconfigured market. However, these scholarly publishers lack the influence to reverse or modify present trends in science and technology publishing.

\section{The bright promise of resource sharing has become quite dim in practice, at least among and between research libraries.}

Efforts on the part of research librarians to reduce the growth of scholarly publication by modifying tenure or promotion requirements or by other means are even less promising. All available analysis demonstrates that scholarly publication has been expanding at its present rate for more than two centuries with no evidence of slackening. It is a function of the continued exponential growth of research and scholarship. ${ }^{4}$ The emphasis on publication, as evidence of research, is an effect, not a cause. For re- search librarians to suggest otherwise is fundamentally insulting to scholars. The argument will marshall little support, but it will engender enmity. Unsurprisingly, scholars confronted with such suggestions react by telling librarians to concentrate their efforts on securing more acquisitions funds.

Sufficient federal funding will probably not be available to solve the research librarian's problem. The prospects of a peace dividend have disappeared in the face of war in the Persian Gulf and the enormity of the national debt. After the war bills are paid, a variety of urgent social needs will compete for the shrinking dollars available at both the federal and the state levels. Not only research libraries, but higher education in general, seems to be in an extended period of increasing fiscal difficulty.

Up to this point, technology generally has been discounted as a near-term solution to the research librarian's serials problem. ${ }^{5}$ Although electronic publication and communication are increasing, they seem only to add to, rather than diminish, the proliferation of materials that research libraries must acquire, including the added costs involved in maintaining and servicing electronic, as well as print, collections. Nevertheless, the new technology offers the opportunity to free research librarians from the enormous financial burdens of acquiring and maintaining large on-site collections. However, discussion of these solutions has generally been limited, vague, and wanting in practical specificity.

\section{RESOLVING THE DILEMMA}

Certainly, all of these factors contribute to research librarians' lack of conviction about their ability to cope effectively with the serials crisis. This lack of conviction, however, extends beyond serials and the present crisis. Research librarians are increasingly aware that they are losing ground in their historic struggle to acquire, preserve, and maintain the record of scholarship. Science serials produced by commercial publishers are certainly the focus of the present difficulty. However, this is only the tip - in fact, minuscule tip - of an enormous iceberg. Furthermore, the ap- 
parent absence of viable means to deal with this still relatively small part of the problem suggests a dimension of intractability that transforms the crisis into a dilemma, without possible resolution. Research librarians increasingly feel that they are doomed to a continuing, losing struggle. They see their critical role in the system of scholarly communication declining, and they feel powerless to prevent it.

Research librarians can, however, resolve their dilemma. Furthermore, in doing so, they will not only solve the serials crisis once and for all, but they will also strengthen their role in the scholarly communication system and improve that system for the benefit of its other participants - scholars and scholarly publishers. They will do this by fundamentally reshaping the research library to take advantage of the capabilities and to respond to the requirements of the new electronic era. Electronic technology has many substantial advantages over print as a medium for scholarly communication. It is much faster, offering the capability of almost instant information delivery anywhere in the world. It is more flexible, providing correspondents with the opportunity to respond either immediately or at their leisure. It is interactive, allowing correspondents to change and adjust text as they converse electronically, and it provides convenient means for concurrent interchange among a number of different parties, who may be widely separated geographically. For these reasons, electronic technology is rapidly becoming the preferred means of informal communication among scholars. ${ }^{6}$

For research librarians, however, the greatest advantage of electronic communication is certainly that a single electronic copy of any scholarly work serves the same function performed by hundreds of copies in hundreds of different research library collections. Indeed, it is this capability that provides research librarians with the means to resolve their long-standing acquisitions dilemma.

Rather than acquiring, organizing, and preserving copies of scholarly works in every research library, as is necessary in the print environment, research librarians can establish, organize, and maintain a single electronic collection. The collection can be immediately accessible to the entire scholarly community. Furthermore, such a collection can be fully cataloged and indexed at a level of detail and with a degree of exactness that are impracticable with a print collection.

Research libraries can, as a consequence, be transformed into information centers. Instead of investing the bulk of their energies and resources in acquiring, organizing, and preserving duplicative and incomplete collections, research librarians can intermediate between scholars and students on the one hand and the central electronic collection on the other to provide any information needed. Through this process, the long-anticipated, but substantially unfulfilled, transformation of the research library from an ownership institution to an access service can be accomplished.

\section{OBSTACLES: REAL OR IMAGINED?}

But is such a transformation possible? Or is there a host of problems in its way, a cluster of insurmountable obstacles that will prevent it from coming to pass? Perhaps, but before dismissing such a reconfiguration of the research library and its role, it is essential to look closely at these presumed obstacles to determine how serious they are and whether they can be overcome.

\section{Technology}

Eirst, of course, is the matter of technology. Can present technology support a single widely accessible and conveniently usable electronic database of scholarship? Clearly, no fundamental technological barriers now stand in the way of such an accomplishment. Already-enormous data storage capacities continue to expand rapidly. Data manipulation is highly sophisticated and becoming ever more so. A network of efficient data communication systems is essentially in place and is constantly improving. Costs in all of these 
areas are declining and should continue to do so. The text of most current scholarly publication presently exists in electronic form as a by-product of the contemporary printing process.

Of course, much would need to be done in order to create an effective and reliable data center. Hardware would have to be acquired and software designed. Arrangements would have to be worked out with scholarly publishers for the deposit of their electronic text. Conversion programs would have to be written to merge the text generated by different publishers, at least until standardization is completed. A communications network would have to be adopted. An electronic bibliographic apparatus would have to be implemented, and services would need to be organized.

None of these requirements, however, is beyond the capability and experience of research librarians working with scholarly publishers and systems designers, and certainly the requirements are not beyond the limits of presently available technology. Indeed, it would be much simpler and more economical to establish and maintain such a central electronic database of scholarly publication than to interact effectively with the decentralized electronic scholarly communication structures that are its only alternative.

\section{Economics}

Even granting the technological feasibility of creating a central electronic database for scholarly publication, its economic viability is surely a matter of serious concern. How much would it cost? Who would pay for it? Might not such an arrangement, in the end, place an even heavier financial burden on the research library?

The 119 largest North American research libraries presently invest approximately one-half billion dollars annually in acquiring and binding print copies of publications for their collections? This resource base should support both the operations of an electronic data center and the communications costs connected with its use. Indeed, even assuming that, for a considerable period of time, research libraries would continue to invest some portion of these funds in print publications not available from the center, sufficient funding should undoubtedly remain to support the center and its use.

Furthermore, as their print acquisitions programs declined, research libraries would generate savings far beyond direct acquisitions expenditure. Reliable, detailed economic data related to research library operations are still difficult to assemble. Yet the researcher can conservatively estimate that 80 percent or more of these North American research libraries' operating budgets, which now total over 1.2 billion dollars, is currently invested in handling printed materials. ${ }^{8}$ This figure includes acquisition, cataloging, circulation, and collection maintenance functions particularly. Although dependence on an electronic data center would not allow these expenditures to disappear all at once or even entirely, they would largely be eliminated over time.

\section{The long-anticipated transformation of the research library from an ownership institution to an access service can be accomplished.}

Of course, under such circumstances, research libraries would generate new costs. The services that they would be required to provide, as the information intermediary between the electronic record of scholarship and the scholar, would not be insignificant. ${ }^{9}$ However, these costs certainly could be covered by materials-handling savings as research libraries gradually are transformed into information centers.

But would such savings actually be realized by research libraries in an electronic information environment? Or would these libraries or their clientele be required to pay use charges for access to the electronic database of scholarly publication - charges that probably would equal or perhaps even exceed the present cost of print acquisitions?

Well over one half of the cost of scholarly publishing presently derives from the production and distribution of print copies. ${ }^{10}$ Conversely, approximately one half of the income generated by scholarly publishing derives from research library purchases. ${ }^{11}$ 
If print distribution were eliminated, scholarly publishers could maintain their vital review and editorial functions without income from libraries, assuming that the publishers did not have to share in the costs of supporting the operations or use of the electronic data center. There would be no need to levy use charges on research libraries or on the scholarly community for access to that center.

\section{Acceptance}

Could scholarly publication effectively continue under such circumstances, without producing and distributing a print product? Would the scholarly community accept such a change? Recent developments suggest that scholars increasingly are making use of electronics for their informal communication. It seems far more likely that scholars will insist on electronic formal communication as well, rather than retain what will, in such an environment, be an increasingly cumbersome print system. ${ }^{12,13}$

Will publishers wish to cooperate in such an endeavor? The answer to that question can be found only in an examination of the structure of scholarly publishing. The vast majority of such publishing, at least in North America, is still in the hands of noncommercial publishers-essentially universities and societies. The dominant objective for these publishers is not generating profit, but contributing to the advancement of scholarship. Indeed, the activities of scholarly publishers are essentially subsidized..$^{14}$ As long as these publishers are able to continue their editorial and review functions, which would not be threatened, they would have no substantive reason not to shift from print to electronic distribution.

Indeed, electronic distribution would offer some significant advantages to the scholarly publisher. The publisher would not have to worry about marketing, reject manuscripts because of budget limitations, or delay the appearance of accepted manuscripts until they could be accommodated in a journal issue. ${ }^{15}$

Of course, commercial publishers would not be willing to participate in an arrangement that would deny them profits. This would certainly pose a problem for an electronic-access system that did not include use charges or some other royalty provision. Although noncommercial publishers produce most North American scholarly publication, this situation does not necessarily obtain elsewhere-particularly in Western Europe. Furthermore, even in North America, commercial publishers produce material that research libraries regularly acquire and preserve.

Commercial publishers participating in an electronic data center should not, however, be an insurmountable problem. All commercial publications could be included in a use-charge system, and the royalties turned over to the appropriate publisher. Such a system could be affordable for libraries. Indeed, such an arrangement might be attractive to commercial publishers, who presently are concerned about controlling access in an electronic distribution environment. ${ }^{16}$ Alternatively, research libraries could continue to acquire and maintain collections of commercial publications in book form, making them available as they do now.

Over time, however, one of the consequences of developing a single electronic database of scholarship might be the gradual disappearance of the commercial scholarly publisher. Such publishers presently exist because universities and societies cannot absorb the full production-distribution responsibility for scholarly publication in a print environment. Absorption of this responsibility by the electronic database center would eliminate the commercial scholarly publisher's function.

\section{Copyright}

Copyright has long - and increasinglyacted as a barrier to the kind of open-access system explicit in an electronic database of scholarship. Will that continue to be the case? Copyright is essential protection for thecommercial author and publisher, who writeand publish in order to make money. The situation is quite different for the scholar and scholarly publisher. The scholar writes and the scholarly publisher publishes in order to contribute to the advancement of knowledge. Both want recognition from their peers, and both know that additional rewards- 
promotion, tenure, salary advancement, academic and professional honors-come as a by-product of such recognition.

Whereas the commercial author or publisher relies on copyright to restrict distribution without payment, the scholar and scholarly publisher are interested in maximizing distribution. Scholars simply wish to ensure that proper attribution is given whenever their work is copied, quoted, or otherwise used. Scholarly publishers share this interest. However, because they function in a free-market guise in the present print information environment, scholarly publishers also have assumed the commercial publisher's interest in preventing unauthorized copying. Indeed, in a print environment, scholarly publishers inevitably have something of a split personality: the merchant, or pseudomerchant, being at odds with the dispenser of knowledge. ${ }^{17}$

With the establishment of an electronic database of scholarly information, which will relieve scholarly publishers of the need to print and distribute their product, these publishers will not require the protections and restrictions of copyright. Furthermore, if commercial publishers are able to secure revenue-in the form of use charges-through participation in the electronic access program, their copyright protection concerns should be fully met.

The lack of accepted standards for electronic publication is also seen as a major barrier to implementing convenient and reliable electronic access. This problem is not fundamental, but derivative. Continued employment of nonstandard hardware and software by scholarly publishers provides protection against unlicensed use of their products. Like copyright, nonstandard equipment ensures that payment is received for use. Because an electronic data center could be organized to eliminate such concerns, it would serve as a strong stimulus to standardization.

\section{WHO LEADS?}

Can the research librarian unilaterally effect such a fundamental change in the research library? Obviously not. The research librarian will require the full and active participation of the scholarly publisher in designing and implementing what also will, necessarily, involve an equally fundamental change in scholarly publishing. Furthermore, changes in both of these activities must be endorsed and supported by scholars. Such support is likely to be forthcoming because of the significant improvements that electronic publication and access would bring to both scholar and publisher and because the present print system is rapidly approaching collapse. ${ }^{18}$

Finally, there is the question of time. How long will it take to move from the print system of scholarly publishing and research library organization to the very different electronic system described above? Even if a major effort were undertaken immediately, it would take a number of years-perhaps two or three decades, at best. First, there would have to be an extended period of negotiation as the scholarly community unites and establishes a direction. A period of extensive planning necessarily follows. Finally, considerable time will be required to carry out the fundamental institutional change. Indeed, the generation of research librarians who begin the process will probably be replaced before it is completed. This provides all the more reason to undertake the effort as quickly as possible.

Clearly, no unconquerable obstacle stands in the way of the changes that will resolve the research librarian's acquisitions dilemma, monumental though these changes will be. The serials crisis demonstrates the need to make such changes, and it indicates steps to be taken in order to carry them out. Research librarians, who understand better than anyone else the critical issues at stake, must provide the necessary leadership to effect this change. Indeed, for research librarians, this challenge is a primary one for the next millennium. 


\section{REFERENCES AND NOTES}

1. Economic Consulting Services, Inc., A Study of Trends in Average Prices and Costs of Certain Serials Over Time; Prepared for the Association of Research Libraries (Washington, D.C.: ARL, 1989); Ann Okerson, Of Making Books There Is No End: Report on Serial Prices for the Association of Research Libraries (Eastchester, N.Y.: ARL, 1989).

2. Richard M. Dougherty, "Editorial," Journal of Academic Librarianship 14:3 (Mar. 1988): "Thus it is possible we are currently struggling through a period of transition, waiting for a new system of scholarly communication to evolve."

3. J. Periam Danton, "University Library Book Budgets, 1860, 1910, and 1960," Library Quarterly 57:284-302 (July 1987).

4. The classic analysis is: Derek J. De Solla Price, Little Science, Big Science ... and Beyond (New York: Columbia Univ. Pr., 1986); and Science since Babylon (New Haven, Conn.: Yale Univ. Pr., 1975). This analysis is confirmed periodically, most recently by Griffiths and King in Okerson, Of Making Books, p.32.

5. A typical assessment is: Gayle Feldman, "The Serials Pricing Controversy," Publishers Weekly 235:70 (Jan. 13, 1989): "Most librarians and publishers agree that an electronic solution in the short-term is pie-in-the-sky."

6. Gina Kolata, "In a Frenzy, Math Enters Age of Electronic Mail," New York Times, June 26, 1990, p.C1, C10.

7. Association of Research Libraries, ARL Statistics, 1988-89 (Washington, D.C.: ARL, 1990), p.31.

8. Ibid.

9. Eldred Smith, The Librarian, the Scholar, and the Future of the Research Library (New York: Greenwood, 1990), p.77-85.

10. Ad Hoc Committee on the Economics of Publication, ed., Economics of Scientific Journals (Bethesda, Md.: Council of Biology Editors, 1982).

11. Ibid.; see also: N. Bernard Basch, "The Scholarly Journal and the Library Market," Scholarly Publishing 19:157-162 (Apr. 1988).

12. William D. Garvey, Communication: The Essence of Science (Oxford: Pergamon, 1979). Garvey's book is an extensive discussion of the informal and formal systems of scholarly communication and of the relationship between them.

13. Kolata, "In a Frenzy," p.C1, C10. As described in this article, the time required for a group of mathematicians, located around the world and interacting via international electronic mail, to solve a major, long-standing mathematics problem, including preparation of a paper to share the results of their work, was less than the time required to publish it in a scholarly journal.

14. Fritz Machlup, "Publishing Scholarly Books and Journals: Is It Economically Viable?" Journal of Political Economy 85:217-25 (Feb. 1977); see also: David W. Lewis, "Economics of the Scholarly Journal," College \& Research Libraries 50:674-88 (Nov. 1989).

15. Thomas P. Stossel, "Speed: An Essay on Biomedical Communication," The New England Journal of Medicine 313:123-26 (July 11, 1985).

16. Robert Weber observed in "The Clouded Future of Electronic Publishing," Publishers Weekly 235:80 (June 29, 1990), that "unless avoidance of copyright were universally detectable, a highly unlikely circumstance, the duplication and distribution of copyright materials seems unstoppable. If this view is correct, publishers would have a powerful disincentive to sell and distribute their wares in electronic form."

17. Frederick A. Praeger, "Librarians, Publishers, and Scholars, Common Interests, Different Views: The View of an Independent Scholarly Publisher," Library Quarterly 54:21-29 (Jan. 1984).

18. Herbert S. White, "Scholarly Publishers and Libraries: A Strained Marriage," Scholarly Publishing 19:125-29 (Apr. 1988). 